\title{
Chickenpox prevention behaviour in the Ras Laffan Industrial City Qatar
}

\section{Djuhari Djuhari1}

${ }^{1}$ Medical Departement Qatar Petroleum

\section{Article Info}

\section{Article History:}

Accepted March 4th, 2020

\section{Keywords:}

Knowledge; Behaviour;

Chickenpox

\begin{abstract}
Chickenpox is a highly contagious infectious disease caused by the Varicella Zoster virus, characterized by a characteristic eruption on the skin and can affect people of all ages. Increasing knowledge and behaviour to prevent chickenpox transmission is very important for mining workers, especially in their accommodation environment. The purpose of this study was to determine the relationship between knowledge of mining workers and prevention behaviour of chickenpox transmission. The type of research used is associative descriptive. The respondents of this study were 67 mining workers who lived in the Ras Laffan Industrial City Qatar accommodation, which were obtained through total sampling. The results showed that there was a relationship between knowledge and the behaviour to prevent chickenpox transmission with a significant value of $p=0.023, p<\alpha(0.05)$. Suggestions for workers in the Ras Laffan Industrial City Qatar accommodation environment, especially those related to preventing the transmission of chickenpox, should be more aware of the very fast transmission of chickenpox.
\end{abstract}

\section{INTRODUCTION}

Chickenpox is derived from the language of Latin, Varicella. ${ }^{1}$ This disease $s$ known by the term Chickenpox Chickenpox. ${ }^{2}$ Varicella is a disease infections are very contagious that is caused by a virus Varicella Zoster, is characterized by the eruption of the typical on the skin. Disease Chickenpoxcan attack all layers of age, but generally the disease is attacking the children. 3,4

The incidence of chickenpox in the world is still high. ${ }^{5-7}$ he number of cases of Chickenpox were registered in Qatar has always increased in three years last, began the year 2012 to 2014. The high number of

Corresponding author:

Djuhari

djuharie@yahoo.com

South East Asia Nursing Research, Vol 2 No 1, March 2020

ISSN:2685-032X

DOI: https://doi.org/10.26714/seanr.2.1.2020.33-38 events that require measures of prevention and treatment is good. ${ }^{7}$

Symptoms of chickenpox water usually begin to appear in time 10 to 21 days after the body infected with the virus varicella. Symptoms are usually in the form of fever, no appetite eat, myalgia, sore head. But in the case of Chickenpox adults complaint, a major form of the sense of pain that is experienced will be very beyond ordinary. The pain will sometimes go away for a long time, even though the other main complaints have reduced or disappeared. . $^{4,8}$

Qatar is one of the destinations for migrant workers. A large number of workers migrant The cause needs service health 
increased. ${ }^{9}$ The labor migrants are generally working in the sectors of industry and construction, as well as maid house stairs. In general, the worker or workers migrants are not aware or less aware of things that relate to the importance of maintaining the health of the body as well as a history of immunization were obtained in the past. In addition to the condition of a place to stay they were overbooked can accelerate the process of transmission of Chickenpox. Displacement of the population of workers migrant can improve the transmission of disease from one place to place another. ${ }^{10}$

Based on a survey conducted in the environment accommodation of workers mining Ras Laffan Industrial City Qatar found the number of visits patients were infected with chickenpox water to $\mathrm{Al}$ Madinah Medical Center in Ras Laffan Industrial City the period of January through to December 2011 Google Translation vary each month. The average number of visits patients pox water ranging from 5 of total visits as many as 67 people each month. ${ }^{11}$

From the results of the survey in the field against the worker's mine who came for treatment to the clinic Al Madinah Health Center Ras Laffan, is found among workers mine who suffered from Chickenpox and workers are not suffering from Chickenpox mingle and interact with one each other without using a tool of protection themselves. They seem less understanding about what the disease Chickenpox, means of transmission and how to prevent it.

The objective of this research is to know the relationship between knowledge about how the prevention of transmission of Chickenpox with behavioural prevention of transmission of chickenpox.

\section{METHODS}

This study has used an associative descriptive research design. This study has used a cross-sectional approach. This study measures respondents' knowledge about the transmission and prevention of chickenpox and their prevention behaviour.

Respondents research it is working mine who worked and lived in the neighbourhood for accommodation Ras Laffan Industrial City Qatar both were infected with Chickenpox and were not infected with Chickenpox. The number of research respondents was 67 people. Technics taking samples which have been used in research this is a total sampling.

The instrument of research that has been used in research this is a questionnaire. The research instrument consisted of 24 statement items. The questionnaire has been declared valid and reliable. The questionnaire has been carried out by expert tests to assess content validity. Then a questionnaire carried out a test try instrument to assess the construct validity. The results of the instrument validity test showed that the research instrument had a value of $r=0.367-0.853$ with a Cronbach Alpha value $=0.957$.

Researchers have explained to prospective respondents before the retrieval of data. It consists of: the purpose of research, benefits of research, and the consequences that should be done during becoming respondents. Respondents who had been willing to be the subject of study are required to sign pieces of informed consent. Researchers keep the identity of respondents in the research data a secret.

The process of making the data has been carried out for one month. Data result of research has been carried out the analysis using a test correlation Spearman rho. The test is performed to determine the relationship between knowledge workers about transmission and prevention of disease Chickenpox with behaviours to prevent disease Chickenpox. 


\section{RESULTS}

This research is carried out in the area of accommodation Mine Qatar Ras Laffan City, where the entire respondents were taken researchers are workers mine who works at Ras Laffan Industrial City. Research carried out in the period of February through to December 2017 with the number of respondents as many as 67 people.

Data were taken from 67 respondents were divided into three characteristics respectively: by Status of Citizens State of respondents who made the object of research the majority are citizens of the State of India as many as 30 people, followed Philipines and Nepal, each of which amounted to 15 people, citizens of the State of Sri Lanka as many as 3 people and finally 2 citizens of Pakistan and Bangladesh each. , The level of education is based on the level of education the majority of educated high school many as 33 people, SMP many as 11 people, Diploma as many as 10 people, Bachelor of as many as nine people and the last elementary school as much as 4 people and group work. Based on the type of work the majority of the respondents work in class Employee Staff (Labor) for 53 people and remaining there in the group of senior staff of as many as 14 people.

Results of the study showed that the level of knowledge workers mine on how the prevention of transmission of Chickenpox are divided into two groups, namely high and low. From the results of data processing, it is known that 60 people $(89.6 \%)$ have low knowledge and 7 people $(10.4 \%)$ have high knowledge. The values Mean knowledge about how the prevention of transmission of Chickenpox workers mine for 1.10 then the value median of 1.00. A minimum value of knowledge workers mines on how the prevention of transmission of Chickenpox by 1 and the value of a maximum of 2 , while the standard deviation ranging from 0308.
Results of the study show the behaviour of the prevention of the transmission of Chickenpox be categorized into two groups, namely low and high. From the results of the processing of the data is known behaviour of prevention of transmission of Chickenpox workers mine low as 57 people (85.1\%) and 10 men (14.9\%) with behavioural prevention high. Then the obtained value Mean of 1.15, and the value of median of 1.00. Minimum value 1 and the value of maximum 2, while the standard deviation of 0.359 .

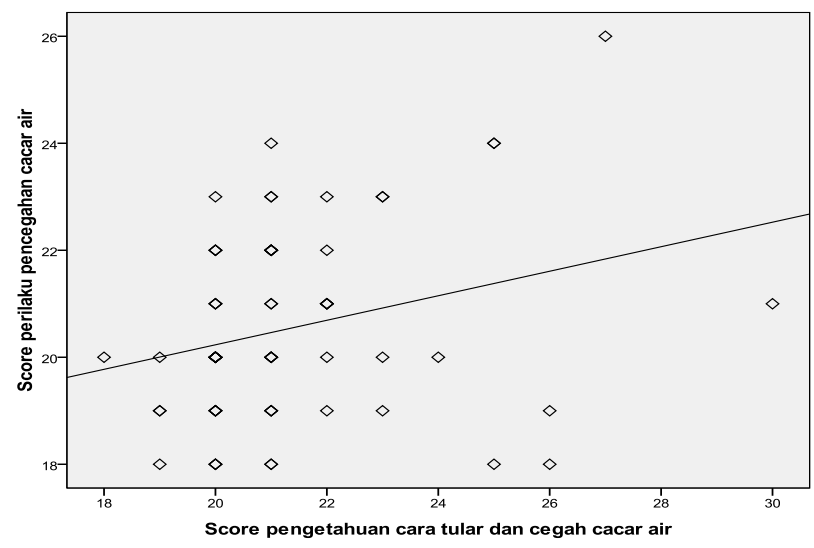

Figure 1

The Relationship between Knowledge About Prevention of Chickenpox Transmission with Chickenpox Prevention Behaviour

\section{DISCUSSION}

The results of the analysis test using Spearman's rho showed a significance value of 0.023 is following the theory that the $p$ value is less than 0.05 , which means that Ho refused to conclude there is a relationship between knowledge workers mine about ways of transmission and prevention of transmission of disease chickenpox with behavioural prevention of chickenpox in the environment of accommodation Ras Laffan Industrial City Qatar.

The result shows knowledge of the workers mine on how the prevention of transmission of the disease chickenpox known to generally low $89.6 \%$, regard this possibility which becomes the cause of the disease chickenpox is still spreading in the 
environment accommodation of workers mining Ras Laffan Industrial city of Qatar. While the data supporting such as Status of Citizens State, level of education, Group Works by answers to a questionnaire on knowledge about how the prevention of transmission of chickenpox was distributed to those obtained frequency level of knowledge of the majority of the low of 60 $(89.6 \%)$ of the total frequency is $67(100$ $\%)$, the value of Mean of 1.10 , the value Median 1.00 and standard deviation of 0.308 , it can be described that the level of education, nationality and type of work does not affect the level of knowledge workers mine on how the prevention of transmission of chickenpox.

Knowledge is an effort that underlies a person's thinking is scientific, while its level depends on scientific knowledge or basic education people are. ${ }^{12}$ Heigh and the low level of knowledge of the workers mine against disease chickenpox depends on the information that is received and does not depend on the level of education of each individual. This means that not all workers mine who has a level of education is high know about how the prevention of transmission of chickenpox much better than the worker's mine who has a level of education low. ${ }^{13}$

Knowledge is not obtained from education formal course, will however be obtained through education non-formal. Knowledge someone about an object contains two aspects, namely the aspect of positive and aspects negative. The second aspect of this which will determine the attitude of a person, the more many aspects of positive and object are known, then it will lead to an attitude more positive towards the object specified. One form of the object's health can be described by the knowledge that is gained from the experience itself. ${ }^{14}$

Prevention behaviour of chickenpox disease among mining workers such a the research results is generally low $85.1 \%$. Behaviour in here to explain about the role they are to perform the prevention of transmission of chickenpox on worker mine in the environment of accommodation Ras Laffan Industrial City. While the data supporting such as Status of Citizens State, Education Level, Class Works by answers to a questionnaire on knowledge about how the prevention of transmission of chickenpox was distributed to those obtained frequency level of knowledge of the majority of the low of $57(85.1 \%)$ of the total frequency 67 $(100 \%)$, the value of Mean of 1.10 , the value Median 1.00 and standard deviation of 0.308 , it can be described that the level of education, nationality and type of education does not affect the level of behaviour workers mine to attempt the prevention of transmission of chickenpox in the environment accommodation of workers Qatar Industrial City's Ras Laffan mine.

The more low-behavioural prevention of chickenpox water in the environment accommodation of workers mining, the process of transmission and spread of the disease chickenpox becomes very easy. Starting from individual to individual other than spread from the environment one into the environment more.3,15 So it can be concluded lack of behavioural prevention of transmission of chickenpox on worker mine very closely related with the level of knowledge of them against the disease chickenpox, as stated in the above that level knowledge workers mine on how the prevention of transmission of chickenpox against the disease was itself generally low.

It is following studies of other states that the act of a person constituted by what is known and what is considered to be good to him. ${ }^{16,17}$ A person's actions are often interpreted in the same way as one's behaviour. Good health knowledge is directly proportional to health behaviour. ${ }^{18}$ This means that the better a person's knowledge is, the better his health behaviour will be.

Based on the results of the analysis above, the role of health workers, especially nurses 
who work at Ras Laffan Industrial City, is very much needed, especially in terms of providing intensive counselling and socialization on efforts to prevent the transmission of chickenpox in the accommodation environment of mining workers in Ras Laffan Industrial City Qatar. Starting from providing information about chickenpox covering the causes, symptoms and signs of someone having chickenpox, the mode of transmission, the complications caused to how to prevent the transmission of chickenpox to all mining workers in the Ras Laffan Industrial City Qatar accommodation environment.

Emphasizing the importance of implementing a clean and healthy lifestyle to mining workers both in times of health and illness. Especially for mining workers infected with chickenpox, they should comply with all instructions given by health workers such as washing hands before and after carrying out activities, always being in an isolation room during the treatment period, always using personal protective equipment such as masks when meeting visiting guests., changing clothes every day, cutting fingernails and so on related to personal hygiene.

Through the above activities, it is hoped that the knowledge of mining workers about how to prevent the transmission of chickenpox will increase, it is hoped that it will lead to positive behaviour among mineworkers regarding efforts to prevent chickenpox transmission in their accommodation environment. The final result expected from all of the above actions is of course to minimize the incidence of chickenpox transmission in the Ras Laffan Industrial City Qatar accommodation, which will also greatly affect the work productivity of mining workers at Ras Laffan Industrial City.

\section{CONCLUSION}

The results showed that knowledge has a unidirectional relationship with the prevention behaviour of chickenpox in the accommodation environment of Las Laffan industrial city Qatar. The level of knowledge of respondents about how to prevent chickenpox transmission in the Ras Laffan Industrial City Qatar accommodation environment is generally still low, while the level of behaviour to prevent chickenpox transmission is generally also low.

Considering that the results of this study are very meaningful towards efforts to reduce the number of people with chickenpox in the Ras Laffan Industrial City Qatar accommodation environment, the participation of health workers, especially nurses who work at Ras Laffan Industrial City, is very much needed, especially in terms of providing intensive counselling and socialization of efforts. prevention of transmission of chickenpox in the accommodation of mining workers in the Ras Laffan Industrial City Qatar. Always emphasize the importance of implementing a clean and healthy lifestyle for mining workers both in times of health and illness.

\section{ACKNOWLEDGMENTS}

I would like to express our appreciation to all respondents who participated in this research and to all units that have supported the implementation of this research.

\section{CONFLICTS OF INTEREST}

Neither of the authors has any conflicts of interest that would bias the findings presented here.

\section{REFERENCES}

1. Kennedy PGE, Gershon AA. Clinical features of varicella-zoster virus infection. Viruses. 2018;10(11):609.

2. Presterl E, Diab-El Schahawi M, Lusignani LS, Paula H, Reilly JS. General Definitions. Basic Microbiol Infect Control Midwives. Published online 2018:1.

3. Yang J, Liu J, Xing F, et al. Nosocomial transmission of chickenpox and varicella zoster 
virus seroprevalence rate amongst healthcare workers in a teaching hospital in China. $B M C$ Infect Dis. 2019;19(1):1-7.

4. Duncan DL. Chickenpox: Presentation, transmission, complications and prevention. $\mathrm{Br}$ J Sch Nurs. 2019;14(10):482-485.

5. Królasik A, Paradowska-Stankiewicz I. Chickenpox in Poland in 2016. Przegl Epidemiol. 2018;72(3). doi:10.32394/pe.72.3.5

6. Bogusz J, Paradowska-Stankiewicz I. Chickenpox in Poland in 2017. Przegl Epidemiol. 2019;73(4). doi:10.32394/pe.73.38

7. Sallam M, Nadeem S, Kumar N. Epidemiological situation of chickenpox in Qatar (2012-2014). J Emerg Med Trauma Acute Care. 2016;2016(2):5. doi:10.5339/jemtac.2016.icepq.5

8. Ballestas HC, Caico C. Pathophysiology of Nursing.; 2014.

9. Ali FMH, Nikoloski Z, Reka H. Satisfaction and responsiveness with health-care services in Qatar-evidence from a survey. Health Policy (New York). 2015;119(11):1499-1505.

10. Goodman A. The development of the Qatar healthcare system: a review of the literature. Int J Clin Med. 2015;6(03):177.

11. RLMC C. RLMC-Rashid Latif Medical College.

12. Hyde L. Chapter 2 - Information as a Commodity. In: Phelps S, Hyde L, Wolf JPBT-TI, eds. Chandos Publishing; 2018:19-30.
doi:https://doi.org/10.1016/B978-0-08101282-6.00002-5

13. Shin J, Dronjic V, Park B. The interplay between working memory and background knowledge in L2 reading comprehension. TESOL $Q$. 2019;53(2):320-347.

14. Boyd G, Heaton PA, Wilkinson R, Paul SP. Nursing management of childhood chickenpox infection. Emerg nurse J RCN Accid Emerg Nurs Assoc. 2017;25(8):32-41.

15. Stryczyńska-Kazubska J, Małecka I, Biskupska M, Bilski B, Pietrzycka D, Wysocki J. Can a healthcare worker be a source of an infection of a patient-a risk of transmitting the chickenpox and shingles virus VZV by the staff of hospital wards-preliminary research findings. J Med Sci. 2017;86(1):30-35

16. Jahan Y, Rahman A. Management of dengue hemorrhagic fever in a secondary level hospital in Bangladesh: A case report. IDCases. 2020;21:e00880. doi:10.1016/j.idcr.2020.e00880

17. Randolph PK, Hinton JE, Hagler D, et al. Measuring competence: collaboration for safety. J Contin Educ Nurs. 2012;43(12):541547, quiz 548-549. doi:10.3928/0022012420121120-79

18. Glanz K, Rimer BK, Viswanath K. Health Behavior: Theory, Research, and Practice. John Wiley \& Sons; 2015. 